\title{
Large-Eddy Simulation of Flow and Pollutant Transport in Urban Street Canyons with Ground Heating
}

\author{
Xian-Xiang Li • Rex E. Britter • Tieh Yong Koh • \\ Leslie K. Norford · Chun-Ho Liu • Dara Entekhabi • \\ Dennis Y. C. Leung
}

Received: 13 December 2009 / Accepted: 3 August 2010 / Published online: 21 August 2010

(C) The Author(s) 2010. This article is published with open access at Springerlink.com

\begin{abstract}
Our study employed large-eddy simulation (LES) based on a one-equation subgrid-scale model to investigate the flow field and pollutant dispersion characteristics inside urban street canyons. Unstable thermal stratification was produced by heating the ground of the street canyon. Using the Boussinesq approximation, thermal buoyancy forces were taken into account in both the Navier-Stokes equations and the transport equation for subgrid-scale turbulent kinetic energy (TKE). The LESs were validated against experimental data obtained in wind-tunnel studies before the model was applied to study the detailed turbulence, temperature, and pollutant dispersion characteristics in the street canyon of aspect ratio 1 . The effects of different Richardson numbers $(R i)$ were investigated. The ground heating significantly enhanced mean flow, turbulence, and pollutant flux inside the street canyon, but weakened the shear at the roof level. The mean flow was observed to be no longer isolated
\end{abstract}

X.-X. Li (ه)

CENSAM, Singapore-MIT Alliance for Research and Technology, S16-05-08, 3 Science Drive 2,

Singapore 117543, Singapore

e-mail: lixx@smart.mit.edu

R. E. Britter

Department of Urban Studies and Planning, Massachusetts Institute of Technology, Cambridge, MA, USA

T. Y. Koh

School of Physical and Mathematical Sciences, Nanyang Technological University,

Singapore 637371, Singapore

L. K. Norford

Department of Architecture, Massachusetts Institute of Technology, Cambridge, MA, USA

C.-H. Liu · D. Y. C. Leung

Department of Mechanical Engineering, The University of Hong Kong, Pokfulam Road,

Hong Kong, China

D. Entekhabi

Department of Civil and Environmental Engineering, Massachusetts Institute of Technology, Cambridge, MA, USA 
from the free stream and fresh air could be entrained into the street canyon at the roof-level leeward corner. Weighed against higher temperature, the ground heating facilitated pollutant removal from the street canyon.

Keywords Ground heating · Large-eddy simulation · Pollutant dispersion · Unstable stratification · Urban street canyon

\section{Introduction}

Continuing urbanization has made urban environment research increasingly popular (Britter and Hanna 2003). As the typical element of the urban area, the street canyon exhibits a distinct climate where microscale meteorological processes dominate (Oke 1988). Air circulation and temperature distribution within urban street canyons are of great significance for pedestrian comfort. Thermal stratification (due to solar radiation, release of stored heat and anthropogenic heat) plays an important role in the air flow and pollutant dispersion processes. Usually the traffic exhaust is hotter than the ambient air and this fact also influences the pollutant transport in urban areas. During the field measurements carried out by Niachou et al. (2008), thermally unstable conditions in the atmospheric boundary layer were measured in $85 \%$ of cases in the daytime, while during the night this value was still $64 \%$. Therefore, it is very important to study the effect of unstable thermal stratification on the urban environment, especially the flow and pollutant dispersion in street canyons.

Numerous field measurements (DePaul and Sheih 1985; Qin and Kot 1993; Xie et al. 2003), laboratory experiments (Meroney et al. 1996; Pavageau and Schatzmann 1999; Kastner-Klein et al. 2001; Li et al. 2008a), and computational fluid dynamics (CFD) studies (Sini et al. 1996; Johnson and Hunter 1998; Baik and Kim 1999; Huang et al. 2000; Kim and Baik 2001; Chan et al. 2002; Jeong and Andrews 2002; Chang and Meroney 2003; Li et al. 2005) have been conducted over the past few decades to help understand the flow pattern and pollutant transport inside urban street canyons. Most of these studies were made under isothermal conditions and only a few studies included the thermal effects (Kim and Baik 2001; Kovar-Panskus et al. 2002; Xie et al. 2006, 2007). With the development of computer hardware and algorithms, the CFD technique has become a popular and powerful tool in urban street canyon research due to its efficiency and relatively low cost ( $\mathrm{Li}$ et al. 2006). Indeed, CFD provides a cost-effective platform to investigate the role of thermal effects in street-canyon pollution problems.

Most of the above-mentioned CFD studies were based on numerical methods using the Reynolds-averaged Navier-Stokes equations (RANS), notably the $k-\varepsilon$ model and its variants (e.g., Sini et al., 1996; Li et al., 2005). However, RANS models generally experience inherent limitations in handling flow separation and unsteady turbulent processes (Li et al. 2006). While RANS models have provided many insights into the characteristics of flow and dispersion in urban street canyons, large-eddy simulation (LES) has recently gained popularity in street-canyon studies. The relative advantages of LES over RANS models have been manifested by many previous studies (e.g., Liu et al., 2004, 2005; Cai et al., 2008; Letzel et al., 2008). However, in the study of thermal effects in urban street canyons, LES has had fewer applications than RANS. One example of such a LES study (Ca et al. 1995) was restricted to very simple cases and only averaged quantities were examined. Therefore, LES has not been utilized to its full potential, e.g., the power of handling transient and unsteady processes, as well as providing detailed information on the turbulence structure, which is difficult, if not impossible, to obtain using RANS models. 
Here we utilize LES to investigate the effect of surface heating on the airflow and pollutant dispersion in urban street canyons. The mathematical model and numerical methods are first described in Sect. 2. This model is then validated against wind-tunnel data for a street canyon under unstable stratification, see Sect. 3. Section 4 presents and discusses the detailed flow structure, temperature distribution and pollutant dispersion, while a summary is given in Sect. 5.

\section{Mathematical and Numerical Model}

\subsection{Flow and Scalar Equations}

Large-eddy simulation for incompressible turbulent flow based on a one-equation subgridscale (SGS) model is employed herein. The isothermal version of the model was detailed in $\mathrm{Li}$ et al. (2008b). Using the Boussinesq approximation, the thermal buoyancy forces are taken into account in both the dimensionless Navier-Stokes equations

$$
\frac{\partial \bar{u}_{i}}{\partial t}+\frac{\partial}{\partial x_{j}} \bar{u}_{i} \bar{u}_{j}=-\frac{\partial \bar{p}}{\partial x_{i}}-\frac{\partial \tau_{i j}}{\partial x_{j}}+\frac{1}{R e} \frac{\partial^{2} \bar{u}_{i}}{\partial x_{j} \partial x_{j}}+\frac{g H}{U^{2}} \bar{T} \delta_{i 3},
$$

and the transport equation for SGS turbulent kinetic energy $k_{\mathrm{sgs}}$,

$$
\frac{\partial k_{\mathrm{sgs}}}{\partial t}+\bar{u}_{i} \frac{\partial k_{\mathrm{sgs}}}{\partial x_{i}}=P+B-\varepsilon+\frac{\partial}{\partial x_{i}}\left(\frac{2}{R e_{\mathrm{T}}} \frac{\partial k_{\mathrm{sgs}}}{\partial x_{i}}\right),
$$

together with the continuity equation

$$
\frac{\partial \bar{u}_{i}}{\partial x_{i}}=0
$$

Here, $\bar{u}_{i}$ is the resolved-scale velocity in the $i$ direction, $\bar{p}$ is the resolved-scale modified pressure (normalised by constant density) defined as

$$
\bar{p}=\bar{p}^{*}+\frac{1}{3} \tau_{i i}
$$

(in which $\bar{p}^{*}$ is the resolved-scale static pressure), $\bar{T}$ is the resolved-scale (potential) temperature, $g$ is the gravitational acceleration, and $\delta$ is the Kronecker delta. These equations are expressed in tensor notation so that the indices $i$ and $j$ range over all the spatial dimensions. The reference length scale $H$ (the building height of the street canyon of aspect ratio 1), the reference velocity scale $U$ (free-stream velocity) and the reference temperature $T_{a}$ (the ambient temperature) are employed to make the above equations dimensionless. The Reynolds number is defined as $R e=U H / v$, where $v$ is the kinematic viscosity. Other symbols and terms in Eq. (1) and (2) are as follows:

$$
\begin{aligned}
\tau_{i j} & =\overline{u_{i} u_{j}}-\bar{u}_{i} \bar{u}_{j}, \\
P & =-\tau_{i j} \bar{S}_{i j}, \\
B & =-g v_{\theta} \frac{\partial \bar{T}}{\partial z}, \\
\varepsilon & =C_{\varepsilon} \frac{k_{\mathrm{sgs}}^{3 / 2}}{\ell},
\end{aligned}
$$




$$
\begin{aligned}
\bar{S}_{i j} & =\frac{1}{2}\left(\frac{\partial \bar{u}_{i}}{\partial x_{j}}+\frac{\partial \bar{u}_{j}}{\partial x_{i}}\right), \\
R e_{\mathrm{T}} & =U H / \nu_{\mathrm{T}}, \\
v_{\mathrm{T}} & =C_{k} k_{\mathrm{sgs}}^{1 / 2} \ell, \\
v_{\theta} & =\left(1+\frac{2 \ell}{\Delta}\right) v_{\mathrm{T}} .
\end{aligned}
$$

The length scale is defined as

$$
\ell=\Delta=(\Delta x \Delta y \Delta z)^{1 / 3}
$$

under neutral or unstable stratification (Moeng 1984; Saiki et al. 2000) and thus $v_{\theta}=$ $3 v_{\mathrm{T}} ; C_{k}=0.03$ and $C_{\varepsilon}=1.0$ are model constants (Li 2008; Li et al. 2010).

The conservation equation for pollutant mixing ratio $\bar{c}$ reads

$$
\frac{\partial \bar{c}}{\partial t}+\frac{\partial}{\partial x_{i}} \bar{u}_{i} \bar{c}=-\frac{\partial \sigma_{i}}{\partial x_{i}}+\frac{1}{\operatorname{ReSc}} \frac{\partial^{2} \bar{c}}{\partial x_{i} \partial x_{i}},
$$

where $\sigma_{i}=\overline{u_{i} c}-\bar{u}_{i} \bar{c}$ is the SGS flux and $S c$ is the Schmidt number.

Similarly, a conservation equation for energy

$$
\frac{\partial \bar{T}}{\partial t}+\frac{\partial}{\partial x_{i}} \bar{u}_{i} \bar{T}=-\frac{\partial \pi_{i}}{\partial x_{i}}+\frac{1}{\operatorname{RePr}} \frac{\partial^{2} \bar{T}}{\partial x_{i} \partial x_{i}},
$$

is included to close the equations, where the SGS turbulent heat fluxes are

$$
\pi_{i}=\overline{u_{i} T}-\bar{u}_{i} \bar{T},
$$

and $\operatorname{Pr}$ is the Prandtl number ( $P r=v / \alpha, \alpha$ is the thermal diffusivity). We take $\operatorname{Pr}=0.72$.

Using the eddy-viscosity and eddy-diffusivity assumptions, the SGS momentum fluxes and SGS heat fluxes are then modelled as

$$
\tau_{i j}=-2 v_{\mathrm{T}} \bar{S}_{i j}
$$

and

$$
\pi_{i}=-v_{\theta} \frac{\partial \bar{T}}{\partial x_{i}},
$$

respectively.

The above equations are solved using the Galerkin finite element method. The detailed mathematical formulation of the above equations was discussed in Liu and Leung (2006), Li et al. (2008b) and Li (2008).

\subsection{Computational Domain and Boundary Conditions}

Figure 1 depicts the schematic computational domain used in the current study, which represents a typical street canyon in an idealised manner. The spanwise-homogeneous computational domain consists of a street canyon of height $h$ at the bottom and a free shear layer of depth $h$ above the building. The width of the street is $b$ and its length is $L$. In our study, a street canyon of aspect ratio (AR, $h / b) 1$ with $h=b=H$ is considered.

The background atmospheric flow is simulated in the form of a pressure-driven free stream in the free shear layer only. The approaching flow is perpendicular to the street axis, which results in a free-stream wind speed $U$ in the streamwise direction. The airflow boundary 
Fig. 1 Schematic diagram of the computational domain for the flow and pollutant transport in a street canyon with ground heating

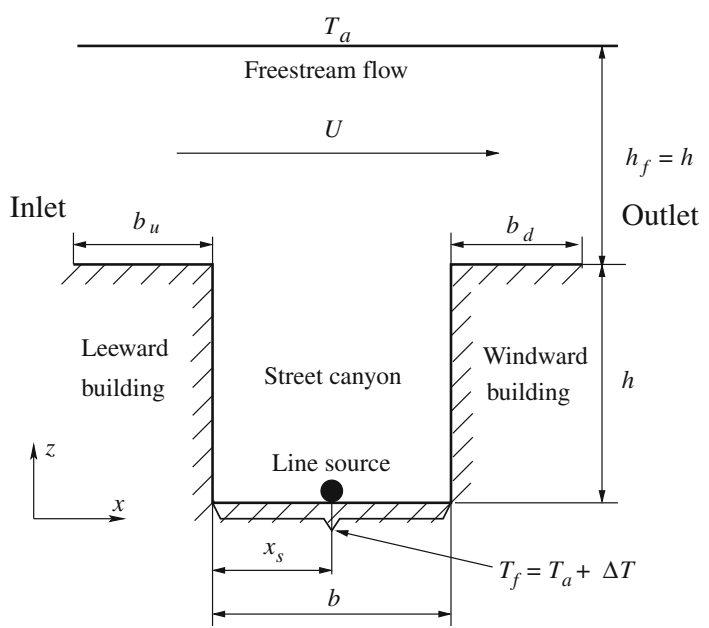

conditions are set to be periodic in the streamwise and spanwise directions, and no-slip conditions are set at all rigid walls. At the top of the domain, a shear-free boundary condition $\left(\partial \bar{u} / \partial z=\partial \bar{v} / \partial z=\bar{w}=0, \partial k_{\mathrm{sgs}} / \partial z=0\right)$ is assumed.

A line source of length $L$ with emission rate $Q$ (that is an emission rate per unit length $Q / L)$ is located on the ground along the street axis at a distance $x_{s}(=b / 2$ in this study) from the leeward building. At the inlet, the temperature is set to $T_{a}$ and pollutant concentration is set to zero (free of pollutant). At the outlet, the convective boundary conditions (Li et al., 2008b) are prescribed for both the temperature and pollutant to ensure that they are convected outside the domain and will not enter into the domain again from the inlet. The air temperature at the top is set to the ambient temperature $T_{a}$ and the ground level (bottom) maintains a constant temperature $T_{f}=T_{a}+\Delta T$ (ground heating). The temperatures at the rigid walls can either be set to a fixed value (ambient temperature $T_{a}$ ) or adiabatic (no heat flux at walls); we take the former situation in the present study.

It is noteworthy that the streamwise boundary conditions for flow field and scalars are different, mainly to be in line with the wind-tunnel experiments reported in the literature. Those wind-tunnel studies investigated the pollutant dispersion from only one street canyon within building arrays (Meroney et al. 1996; Pavageau and Schatzmann 1999). This configuration is the so-called 'urban' context, in contrast to the 'open' or 'rural' settings (Meroney et al. 1996). The focus here is pollutant removal from an urban street canyon, and the background pollutant from the upwind is not considered.

\subsection{Numerical Parameters}

The grid used for the street canyon of aspect ratio 1 consists of $64 \times 32 \times 64$ and $128 \times 32 \times 64$ elements inside and above the street canyon, respectively. The grid is stretched near the wall to better resolve the near-wall turbulence. The minimum grid sizes are $5.319 \times 10^{-3} \mathrm{H}$ in the streamwise and vertical directions and $3.125 \times 10^{-2} H$ in the spanwise direction. The simulation time for the flow to reach pseudo-steady state was about $300 \mathrm{H} / \mathrm{U}$. Another $300 \mathrm{H} / \mathrm{U}$ simulation results were collected to retrieve the statistical flow, turbulence, and scalar properties with a time step of $0.005 \mathrm{H} / \mathrm{U}$. 


\section{Model Validation}

The accuracy of the above model is evaluated using an experimental database obtained by the Japanese National Institute for Environmental Studies in an atmospheric diffusion wind tunnel (Uehara et al. 2000). Their experiment was carried out inside a target street canyon within a model building array and the entire wind-tunnel floor was heated, which is not exactly the same as the configuration described in the previous section. For comparison, the boundary conditions for temperature at the outlet in the LES model are changed to periodic. Thus, the thermal energy convected from the outlet enters the domain from the inlet.

Following Uehara et al. (2000), a bulk Richardson number $R b$ is introduced to quantify the thermal effects, and is defined as

$$
R b=\left(\frac{g h}{U_{h}^{2}}\right) \frac{T_{h}-T_{f}}{T_{a}},
$$

where $T_{h}$ is the temperature at the roof level, and $U_{h}$ is the streamwise velocity at the roof level.

The results from our LES for a street canyon of aspect ratio 1 at $R e=4,000$ and $R b=-0.3$ (which is the closest $R b$ value from a series of numerical experiments) are compared with the experimental data at $R b=-0.21$ (Fig. 2). It is clear that the agreement between the current LES results and the experimental data is good, especially within the street cavity $(z / h<1)$. The well-simulated thermal boundary layer near the ground indicates adequate grid resolution in the current LES. The apparent discrepancy of streamwise velocity above the street canyon $(z / h>1)$ is caused by the different vertical extent above the street canyon used in the experiment, which was $6 h$, and in the current LES, which is $h$. At the model top $(z=2 h)$, a shear-free boundary condition is imposed, which suppresses the development of large eddies in the free stream. In an isothermal water-channel experiment, Li et al. (2008a) reported that, above the street canyon from $z=2 h$ to $z=3 h$, the measured streamwise velocities varied slightly $(<2 \%)$. It seems that when ground heating is present, this conclusion is no longer valid. To predict a more accurate wind field above the street canyon, a larger vertical computational domain is needed.

As demonstrated above, the LES reproduces well the flow and temperature structure in urban street canyons with ground heating. For the pollutant dispersion, the LES model was validated against wind-tunnel measurement under isothermal conditions and good agreement was also observed (Li et al. 2008b). In the upcoming sections, the validated model will be utilized to study in detail the flow, temperature, and pollutant dispersion inside urban street canyons with different levels of ground heating. The boundary condition for temperature at the outlet reverts to the convective type, as described in the previous section.

\section{Results and Discussions}

In this section, in place of $R b$, we introduce another Richardson number

$$
R i=-\frac{g h}{U^{2}} \frac{\Delta T}{T_{a}} .
$$

This definition of $R i$ avoids the use of $U_{h}$, because $\bar{u}$ has a large vertical gradient near $z=h$ (see Fig. 2b) and $U_{h}$ is hard to control and measure in experiments or numerical simulations. The $R i$ number is varied by changing $\Delta T$. Four cases of a street canyon of aspect ratio 1 

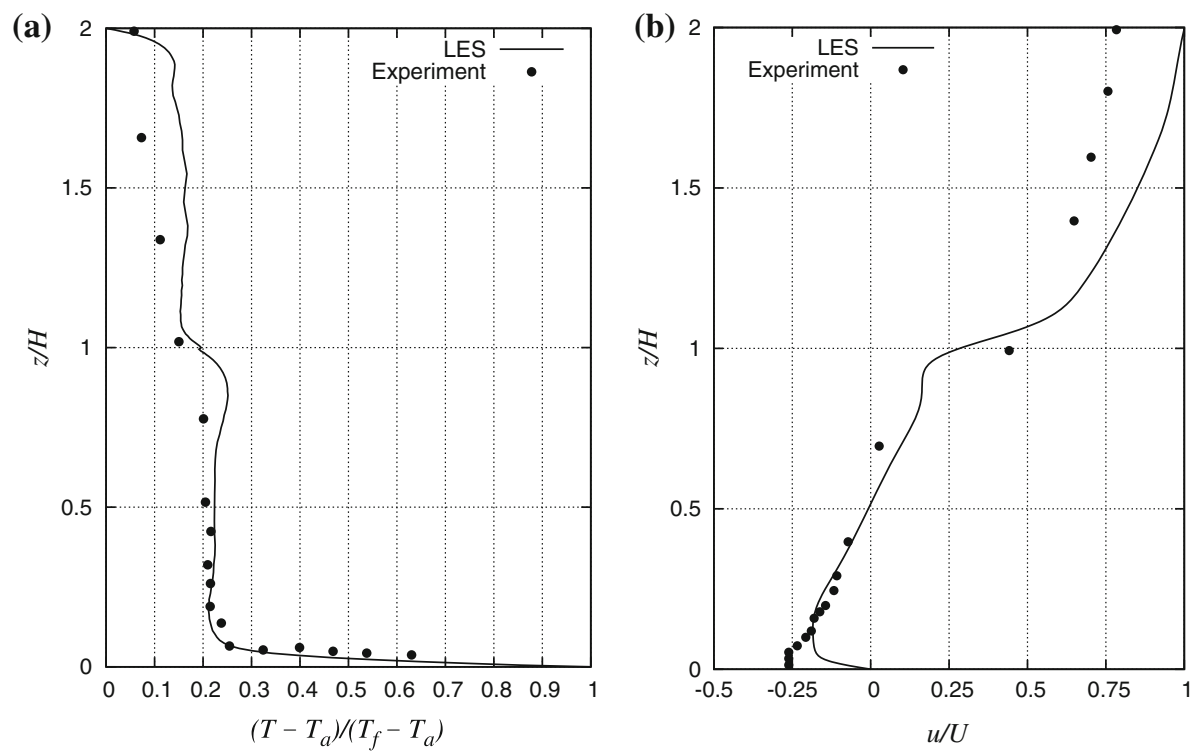

Fig. 2 Vertical profiles of normalised a temperature $\left(\langle\bar{T}\rangle-T_{a}\right) /\left(T_{f}-T_{a}\right)$ and $\mathbf{b}$ streamwise velocity magnitude $\langle\bar{u}\rangle / U$ along the vertical centreline of the street canyon of aspect ratio 1 . The experimental data of Uehara et al. (2000) were at $R b=-0.21$ and the current LES results are at $R b=-0.3$

with different $R i$ numbers are presented and discussed here, i. e., $R i=0,-0.6,-1.2$, and -2.4. The Reynold number $R e$ for these cases varies from 4,000 to 7,000, which complies with the criteria suggested by Hoydysh et al. (1974) to ensure that the flow pattern in the street canyon is independent of viscous effects (Meroney et al. 1996).

In the following discussions, brackets \langle\rangle represent the spanwise and temporal averages of physical properties, while" represents the deviation from their averages.

\subsection{Wind Field}

\subsubsection{Mean Flow}

Figure 3 shows the streamfunction $\psi$, which is defined as

$$
\begin{aligned}
\frac{\partial \psi}{\partial z} & =\langle\bar{u}\rangle, \\
-\frac{\partial \psi}{\partial x} & =\langle\bar{w}\rangle .
\end{aligned}
$$

The streamline patterns show little variation with Richardson number, but the magnitude of the streamfunction at the core region in the street canyon has increased by 2.5 times from $\psi=-0.06(R i=0)$ to $\psi=-0.15(R i=-2.4)$. Figures 4 and 5 show the streamlines; note that there is impingement of fluid onto the top of the windward wall, as indicated by the streamlines. A small region of high upward vertical velocity around this corner can be observed, and is in line with the results of visualization (Sasaki et al. 1989). After impingement, air both descends vertically into the street canyon and flows out of the top of the street canyon (Uehara et al. 2000). 

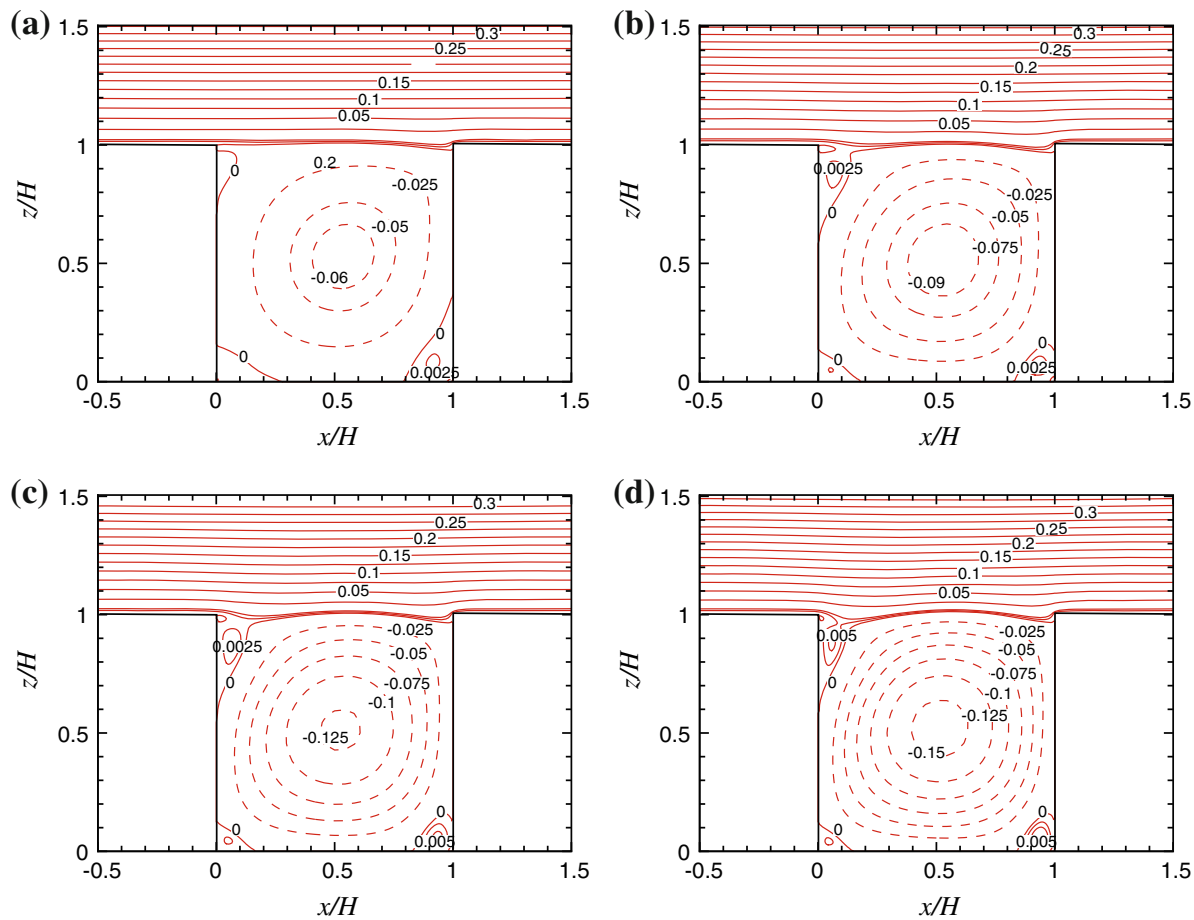

Fig. 3 Spatial distribution of the dimensionless streamfunction $\psi$. Ri: a $0 ; \mathbf{b}-0.6 ; \mathbf{c}-1.2 ; \mathbf{d}-2.4$. Dashed lines indicate negative values (clockwise rotating)

With increasing unstable stratification, the streamfunction pattern significantly changes. In the isothermal case, the zero streamfunction contour covers the entire roof level, together with the parallel iso-streamfunction contours at and above the street canyon, indicating that the recirculation inside the street canyon is isolated from the free-stream flow (Liu et al. 2005). But when ground heating is introduced, the zero streamfunction contour no longer covers the entire roof level and the free-stream flow penetrates into the street canyon at the leeward roof-level corner. This flow pattern may suggest that the mean flow there also transports scalars (temperature or pollutant) from the street canyon across the roof level to the free stream.

Apparently, both the reverse streamwise flow near the ground and the roof-level streamwise flow increase with more negative $R i$ (Fig. 4; note that the scales in some of the plots in this section are slightly different so as to show the variation). The magnitude of the normalised streamwise velocity near the ground increases from about $0.1(R i=0)$ to $0.5(R i=-2.4)$. Significant changes also occur for both upward and downward normalised vertical velocities (Fig. 5). The maximum of the downdraft near the windward wall is considerably larger than that of the updraft near the leeward wall when $R i=0$, but is nearly the same when $R i=-2.4$. The reason for this is that, with ground heating, the buoyancy of air parcels is enhanced. With increasing ground heating, more air has to be moved to the leeward side and then deflected upward (by continuity, as much air moves up on the leeward side as moves down on the windward side). Therefore, the reverse streamwise flow increases with increasing heating intensity. Due to continuity, the roof-level streamwise velocity and vertical velocity near the windward wall increase accordingly. The combined effect of the buoyancy force and 

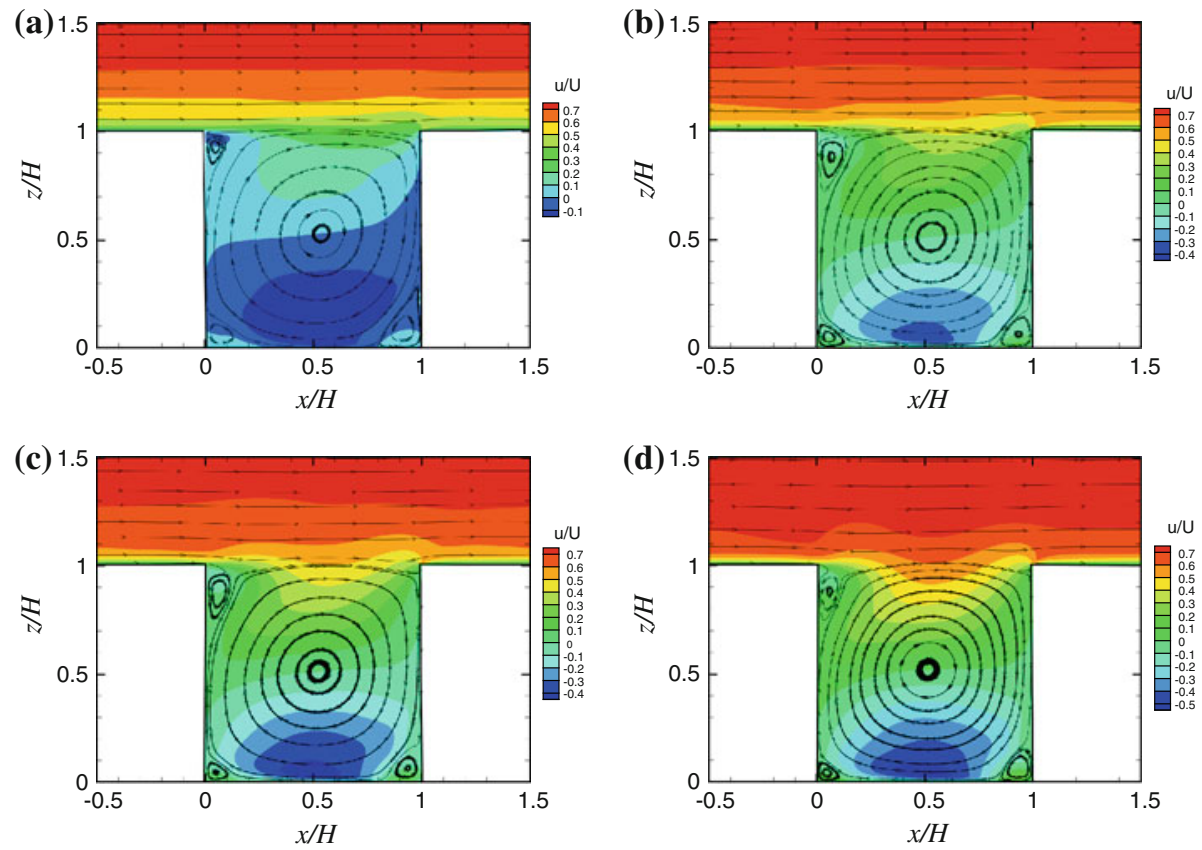

Fig. 4 Flow patterns and normalised streamwise velocities $\langle\bar{u}\rangle / U . R i$ : a $0 ; \mathbf{b}-0.6 ; \mathbf{c}-1.2 ; \mathbf{d}-2.4$
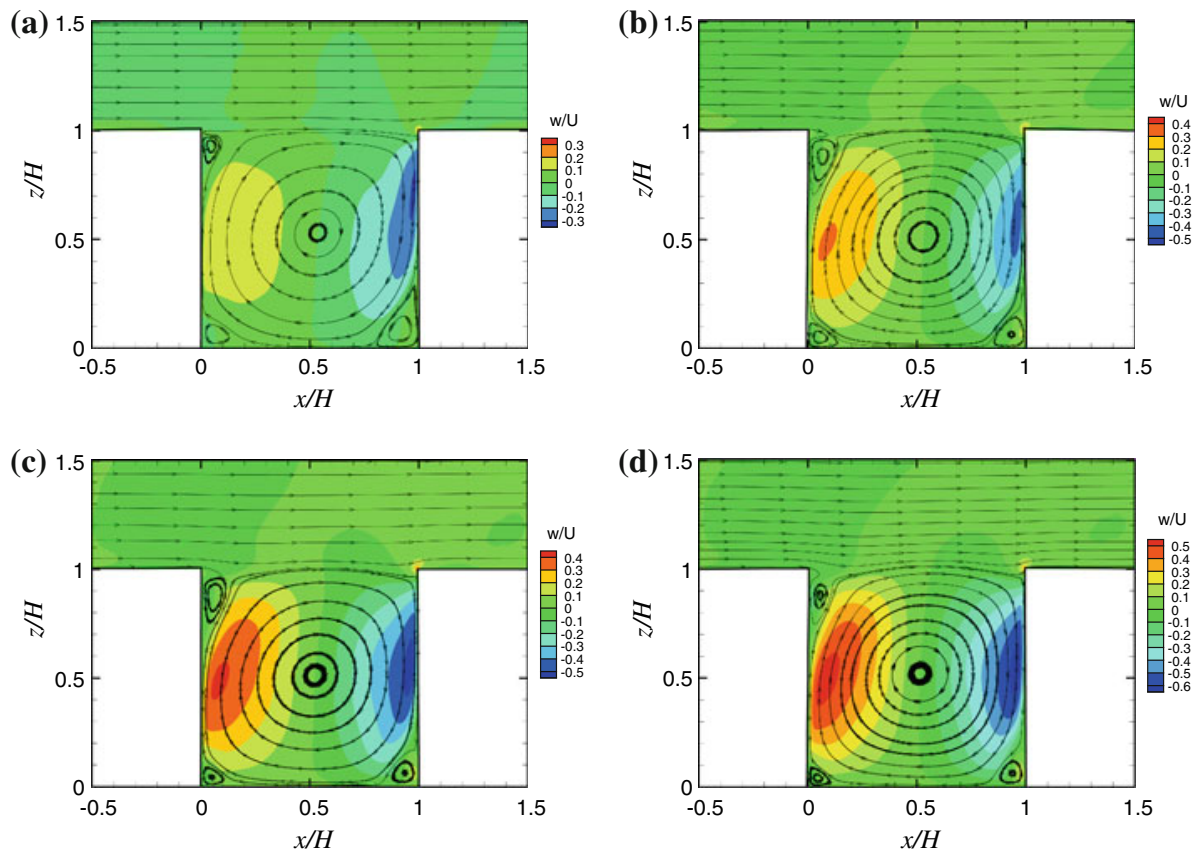

Fig. 5 Flow patterns and normalised vertical velocities $\langle\bar{w}\rangle / U . R i$ : a $0 ; \mathbf{b}-0.6 ; \mathbf{c}-1.2 ; \mathbf{d}-2.4$ 

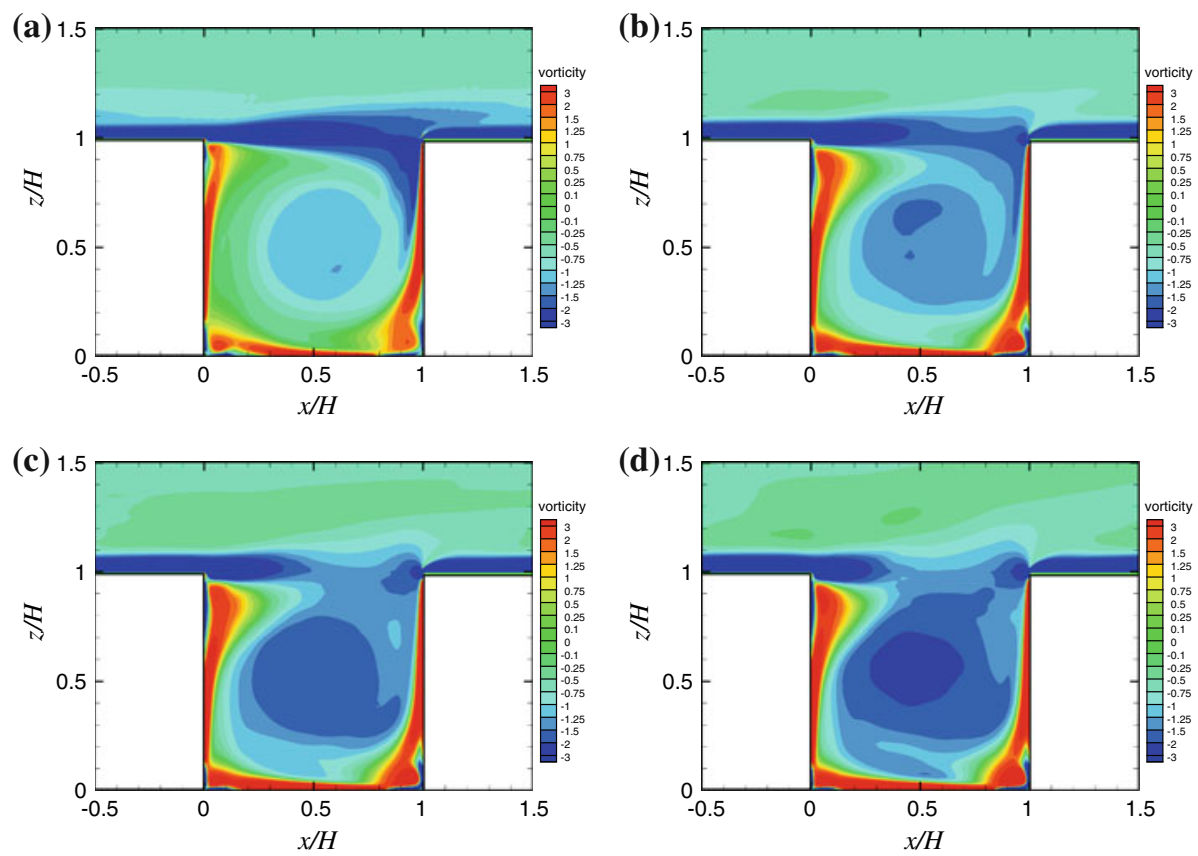

Fig. 6 Normalised mean spanwise vorticity $\omega_{y}$. Ri: a $0 ; \mathbf{b}-0.6 ; \mathbf{c}-1.2 ; \mathbf{d}-2.4$

the mechanical force is that the rate of updraft increment is larger than for the downdraft, making the two comparable when the heating intensity is higher $(R i=-2.4)$.

The strengthened streamwise and vertical motions enhance the pollutant transport inside the street canyon, as demonstrated in Li et al. (2009) and in the upcoming sections.

\subsubsection{Vorticity}

The normalised spanwise mean vorticity

$$
\omega_{y}=\frac{\partial\langle\bar{w}\rangle}{\partial x}-\frac{\partial\langle\bar{u}\rangle}{\partial z}
$$

is shown in Fig. 6. In the isothermal case (Fig. 6a), the LES results agree quite well with the spanwise vorticity measured by Caton et al. (2003, Fig. 5a therein). The layer of large negative vorticity at the roof level indicates a strong shear layer there, but with ground heating, this shear layer becomes weaker. This characteristic may be the reason for better pollutant removal when ground heating is introduced, as will be seen later. Since this shear layer is located where Kelvin-Helmholtz instability occurs (Louka et al. 2000; Letzel et al. 2008), the ground heating may seriously inhibit the growth of this instability.

In the core region in the street canyon, the spiral negative vorticity becomes larger in magnitude with increasing ground heating, which is in line with the streamfunction plot (Fig. 3), confirming the strengthened recirculation. 

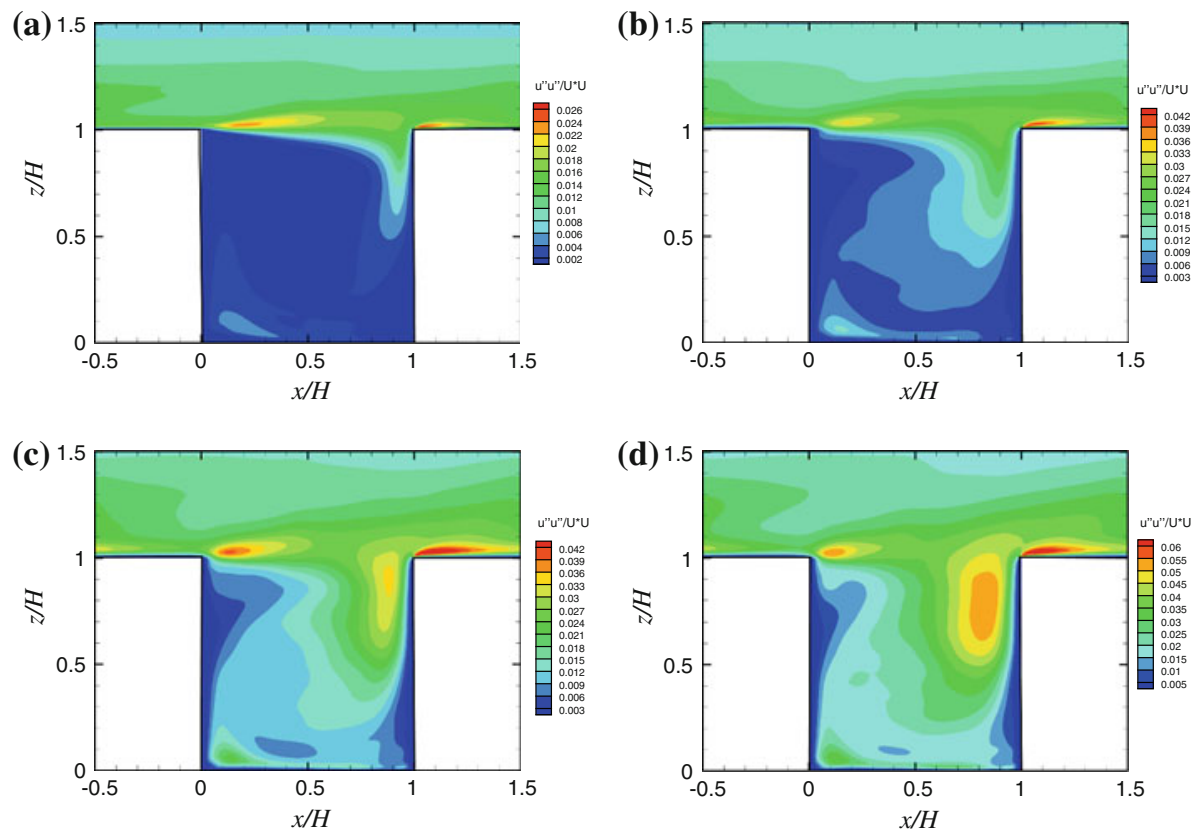

Fig. 7 Normalised streamwise velocity variances $\left\langle u^{\prime \prime} u^{\prime \prime}\right\rangle / U^{2} . R i: \mathbf{a} 0 ; \mathbf{b}-0.6 ; \mathbf{c}-1.2 ; \mathbf{d}-2.4$

\subsubsection{Turbulence}

Figures 7 and 8 depict the normalised streamwise and vertical velocity variances $\left\langle u^{\prime \prime} u^{\prime \prime}\right\rangle / U^{2}$ and $\left\langle w^{\prime \prime} w^{\prime \prime}\right\rangle / U^{2}$ with different values of $R i$. It is evident that both velocity variances are markedly enhanced due to the added turbulence by buoyancy. The most pronounced increases for both variances are observed near the roof level, with streamwise variance at the windward corner and vertical variance at the leeward corner. It is also interesting to note that there are secondary maxima at the diagonally opposite corners for both the streamwise and vertical variances. It is also worthwhile to note that near the roof level, plume-like vertical velocity variance patterns develop in the canyon and then exit to the free stream. This feature may be related to enhanced pollutant removal from the street canyon and is worth further investigation.

Overall, the turbulence is greatly enhanced near the shear layer at the roof level, which is a very important region for both flow and pollutant transport. This will foster mixing and introduce more momentum from the free stream into the canyon, producing increased mean velocities, as seen in the previous section.

\subsubsection{Momentum Flux}

The vertical momentum flux $\left\langle u^{\prime \prime} w^{\prime \prime}\right\rangle / U^{2}$ has a negative maximum near the top leeward corner of the street canyon. This maximum increases with increasing heating intensity and the ratio of the cases with $R i=-2.4$ and $R i=0$ is as large as 3 . The large negative values along the roof level indicate substantial exchange of mass there. Increasing heating evidently has enhanced this exchange. The pollutant flux out of the street canyon is set by the pollutant 

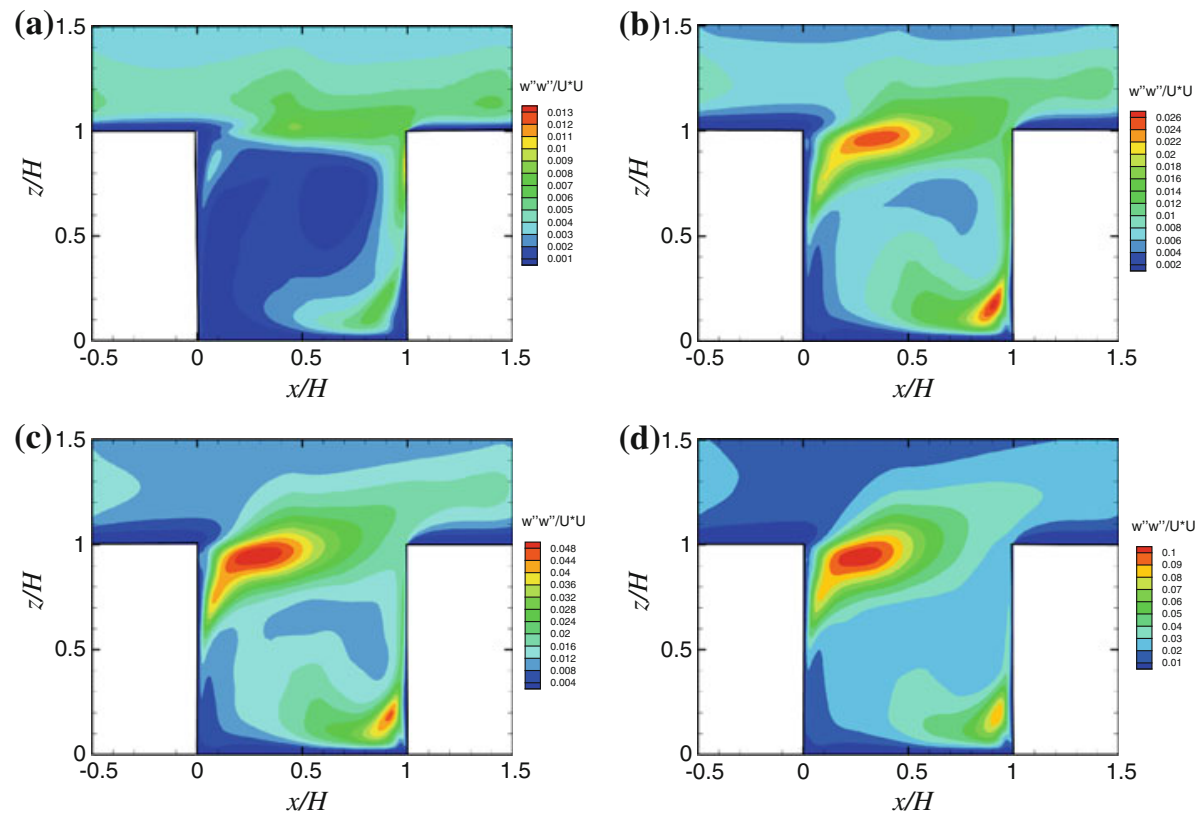

Fig. 8 Normalised vertical velocity variances $\left\langle w^{\prime \prime} w^{\prime \prime}\right\rangle / U^{2}$. Ri: a $0 ; \mathbf{b}-0.6 ; \mathbf{c}-1.2 ; \mathbf{d}-2.4$

flux from the source. Consequently the increased exchange of mass reduces the magnitude of the pollutant concentrations within the street canyon.

On the other hand, the Reynolds stress $-\left\langle u^{\prime \prime} w^{\prime \prime}\right\rangle$ serves as the resistance of the urban canopy to the free-stream flow. With increasing ground heating, this resistance becomes higher and thus higher pressure forces are needed to maintain the same free-stream velocity.

\subsection{Temperature Distribution}

The normalised mean temperature $\left(\langle\bar{T}\rangle-T_{a}\right) / \Delta T$ (Fig. 9) is not greatly affected by the heating intensity. This is because the turbulent and diffusive heat fluxes are both linearly dependent on resolved-scale temperature gradients in this model. Therefore, at pseudo-steady state, the temperature is essentially governed by an elliptic equation. Since the temperature is fixed at the boundary in the cases studied, the solution to the temperature distribution must be basically fixed, and any slight variations of the temperature distribution are due to the differences in advection.

At the lee side of the street canyon, the normalised temperature is higher than at the windward side, which is a result of the reverse streamwise velocity near the ground. In the core region of the street canyon, the normalised temperature was rather uniform (between 0.09 and 0.125). It is interesting to consider the real-life impact of the temperature distribution on the city dwellers in the leeward and windward buildings. In mid-latitude regions, if $\Delta T=20 \mathrm{~K}$ and $T_{a}=290 \mathrm{~K}$ for $R i=-2.4$ (this corresponds to a street canyon of $10 \mathrm{~m}$ high by $10 \mathrm{~m}$ wide and a free-stream velocity of about $1.7 \mathrm{~m} \mathrm{~s}^{-1}$ ), then the temperature difference between leeward and windward buildings could reach about $2 \mathrm{~K}$, which is noticeable to building occupants. However, in tropical regions (such as Singapore), $\Delta T$ cannot be very high and the 

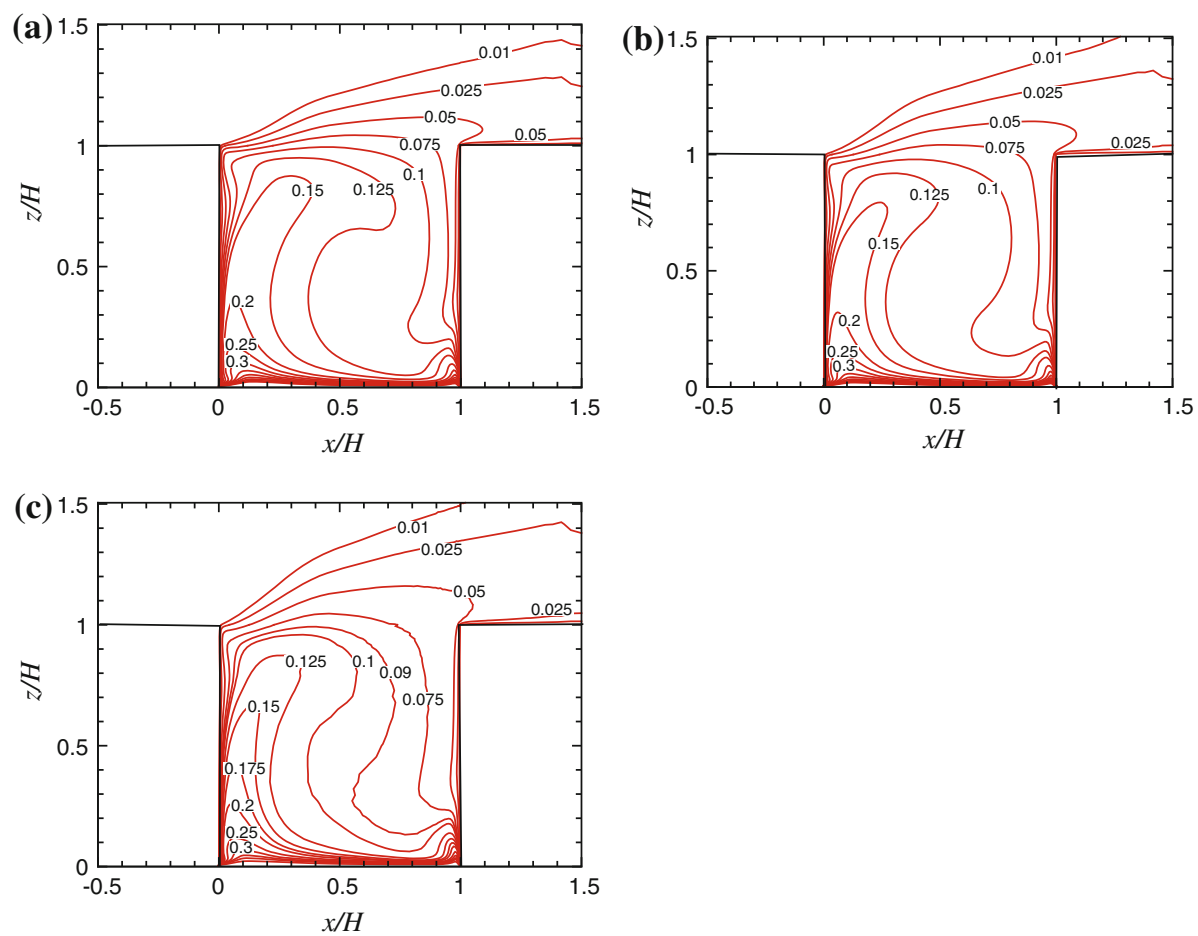

Fig. 9 Normalised mean temperature $\left(\langle\bar{T}\rangle-T_{a}\right) /\left(T_{f}-T_{a}\right) . R i$ : $\mathbf{a}-0.6 ; \mathbf{b}-1.2 ; \mathbf{c}-2.4$

low-level flow is considerably weaker than that in mid-latitude regions (Yi and Lim 2004). If $\Delta T=2 \mathrm{~K}$ and $T_{a}=300 \mathrm{~K}$ for $R i=-2.4$, which corresponds to a street canyon of $10 \mathrm{~m}$ high by $10 \mathrm{~m}$ wide and a free-stream velocity of $0.5 \mathrm{~m} \mathrm{~s}^{-1}$, then the temperature difference between the leeward and windward buildings is only about $0.2 \mathrm{~K}$ and will not be a problem for thermal comfort.

With increasing heating intensity, the normalised temperature inside the street canyon shows a slightly decreasing tendency, which is consistent with experimental data. [See Fig. 6 in Uehara et al. (2000); note that they defined the normalised mean temperature as $(\langle T\rangle-$ $\left.T_{f}\right) /\left(T_{a}-T_{f}\right)$. The sum of the two differently-defined normalised temperatures is 1.] Above the street canyon, a slightly increasing tendency of the normalised temperature is observed, suggesting that, with increasing ground heating, the airflow also transports more heat from the street canyon to the free stream.

\subsection{Pollutant Dispersion}

The normalised mean pollutant concentration fields (Fig. 10) for all the four cases are generally similar, but the magnitude of the mean concentration is markedly less for large negative $R i$ numbers inside the street canyon. Table 1 contrasts the trend of the pollutant ratio inside and above the street canyon, suggesting again that there is greater mixing occurring across the roof level. The effect of ground heating on pollutant dispersion is twofold: ground heating enhances the in-canyon flow advection, which brings pollutants more rapidly to the roof level; 

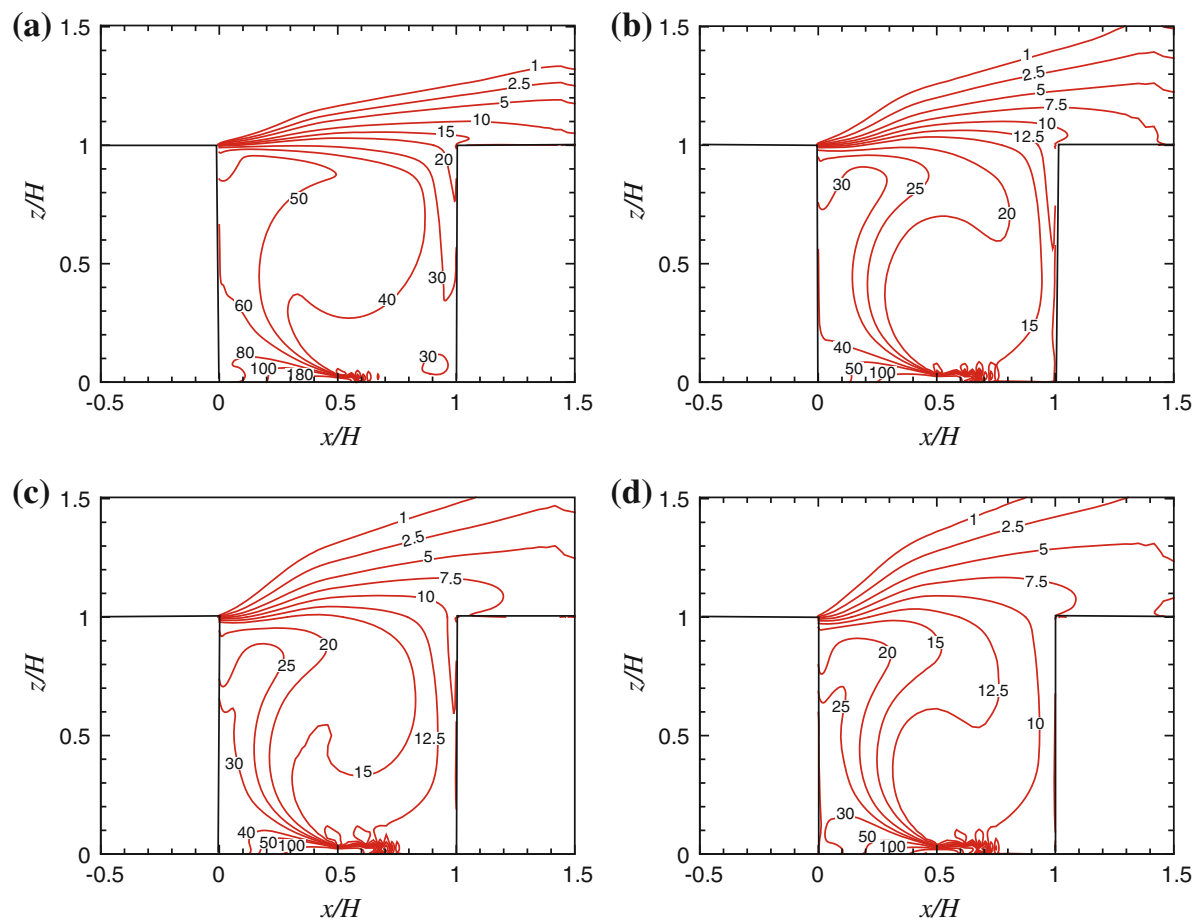

Fig. 10 Normalised pollutant concentration $\langle\bar{c}\rangle U H L / Q . R i$ : a $0 ; \mathbf{b}-0.6 ; \mathbf{c}-1.2 ; \mathbf{d}-2.4$

Table 1 Ratio of pollutants inside and above the street canyon of aspect ratio 1 with different $R i$

\begin{tabular}{lll}
\hline$R i$ & $\begin{array}{l}\text { Pollutant in the } \\
\text { street canyon (\%) }\end{array}$ & $\begin{array}{l}\text { Pollutant in the } \\
\text { free stream (\%) }\end{array}$ \\
\hline 0 & 93.6 & 6.4 \\
-0.6 & 89.3 & 10.7 \\
-1.2 & 86.5 & 13.5 \\
-2.4 & 83.6 & 16.4 \\
\hline
\end{tabular}

and increases the roof-level turbulent diffusion, which is responsible for removing pollutant to the free stream.

To further examine how the buoyancy force enhances pollutant transport, the vertical pollutant fluxes $\left\langle w^{\prime \prime} c^{\prime \prime}\right\rangle(H L / Q)$ for each case are depicted in Fig. 11 for comparison. Under isothermal conditions, there is a strong vertical flux near the windward wall due to the mixing of the pollutant re-entering the street canyon with pollutant-free air from the free stream. However, with ground heating, this strong vertical flux disappears, and instead the vertical flux at the wake of the line source becomes strengthened and strong vertical fluxes are observed along the leeward wall, which is absent from the isothermal case. These are speculated to transport more pollutants from the line source to the roof level. To verify this speculation, the pollutant concentration budgets (by taking an average of the pollutant transport equation, see Li et al. 2009) 

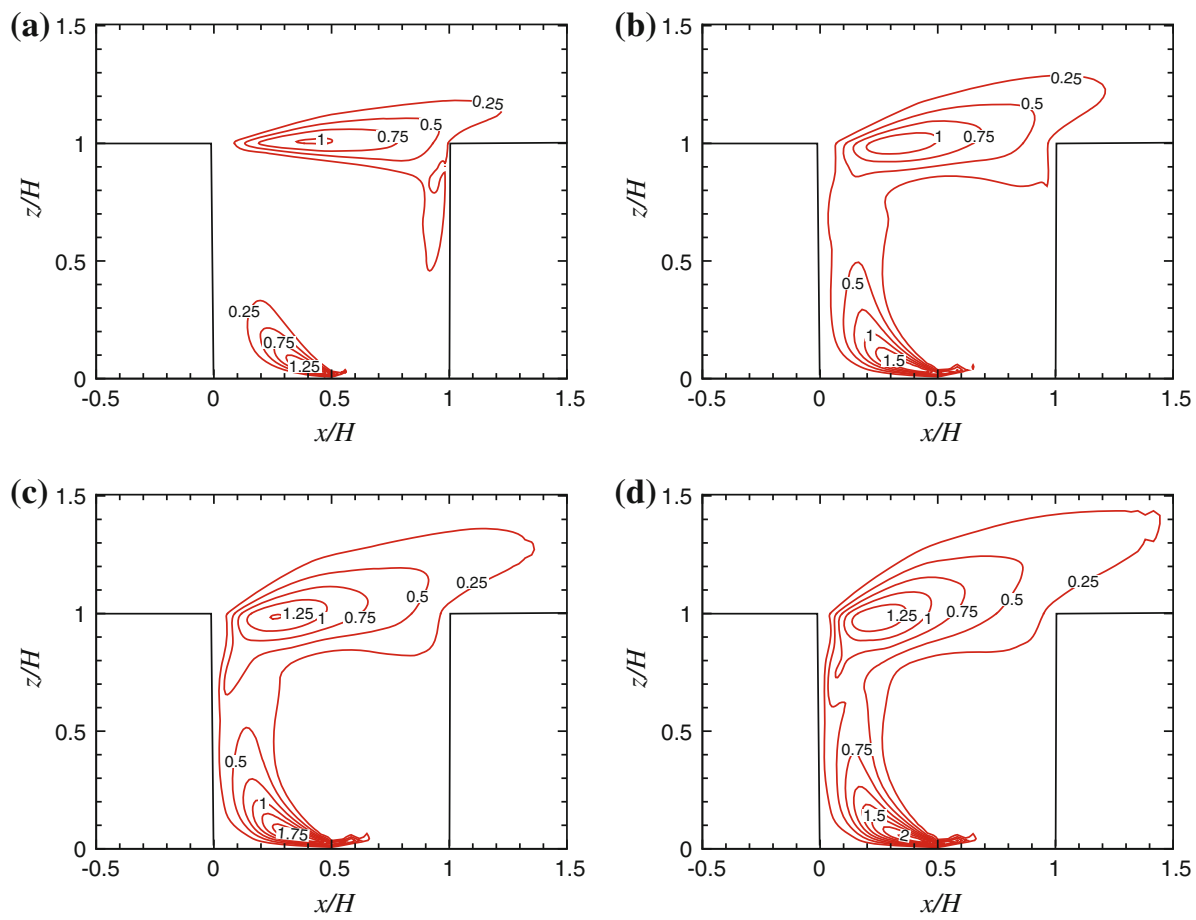

Fig. 11 Normalised pollutant fluxes $\left\langle w^{\prime \prime} c^{\prime \prime}\right\rangle(H L / Q)$. Ri: a $0 ; \mathbf{b}-0.6 ; \mathbf{c}-1.2 ; \mathbf{d}-2.4$

$$
\begin{aligned}
\frac{\partial\langle\bar{c}\rangle}{\partial t}= & \underbrace{-\langle\bar{u}\rangle \frac{\partial\langle\bar{c}\rangle}{\partial x}}_{\text {streamwise advection vertical advection }}-\underbrace{-\langle\bar{w}\rangle \frac{\partial\langle\bar{c}\rangle}{\partial z}-\frac{\partial\left\langle u^{\prime \prime} c^{\prime \prime}\right\rangle}{\partial x}-\left\langle\frac{\partial \sigma_{x}}{\partial x}\right\rangle}_{\text {streamwise turbulent transport }}-\underbrace{\frac{\partial\left\langle w^{\prime \prime} c^{\prime \prime}\right\rangle}{\partial z}-\left\langle\frac{\partial \sigma_{z}}{\partial z}\right\rangle}_{\text {vertical turbulent transport }} \\
& \underbrace{+\frac{1}{\operatorname{ReSc}}\left(\frac{\partial^{2}\langle\bar{c}\rangle}{\partial x^{2}}+\frac{\partial^{2}\langle\bar{c}\rangle}{\partial z^{2}}\right)}_{\text {molecular diffusion }}
\end{aligned}
$$

along the roof level for the cases of $R i=0$ and $R i=-2.4$ are compared in Fig. 12. The most evident change is that, when $R i=-2.4$, the vertical turbulent diffusion exhibits a strong positive value at the leeward corner, showing that there is a significant increase in pollutant concentration there. Another important point in Fig. 12b is the function of vertical advection at $0 \leq x / H \leq 0.17$, where the vertical advection has a large negative contribution to the concentration budget. Since $\langle\bar{w}\rangle$ in that interval is negative (Fig. 5d), this suggests that fresh air is entrained into the street canyon at this leeward corner, which dilutes the pollutant there. The observation mentioned in Sect. 4.1.1 is supported here, that the mean flow field in the street canyon is no longer isolated from the free stream when ground heating is involved.

It has been demonstrated here that the role of natural and anthropogenic heating sources in modifying dispersion in the street canyon should be given some attention. Although the ground heating helps better disperse the pollutant, one must bear in mind that the increasing temperature may also make the environment thermally uncomfortable to pedestrians and city dwellers in mid-latitude regions. While it may be feasible to achieve the same enhancement to pollutant dispersion without seriously deteriorating the thermal comfort in tropical regions, 

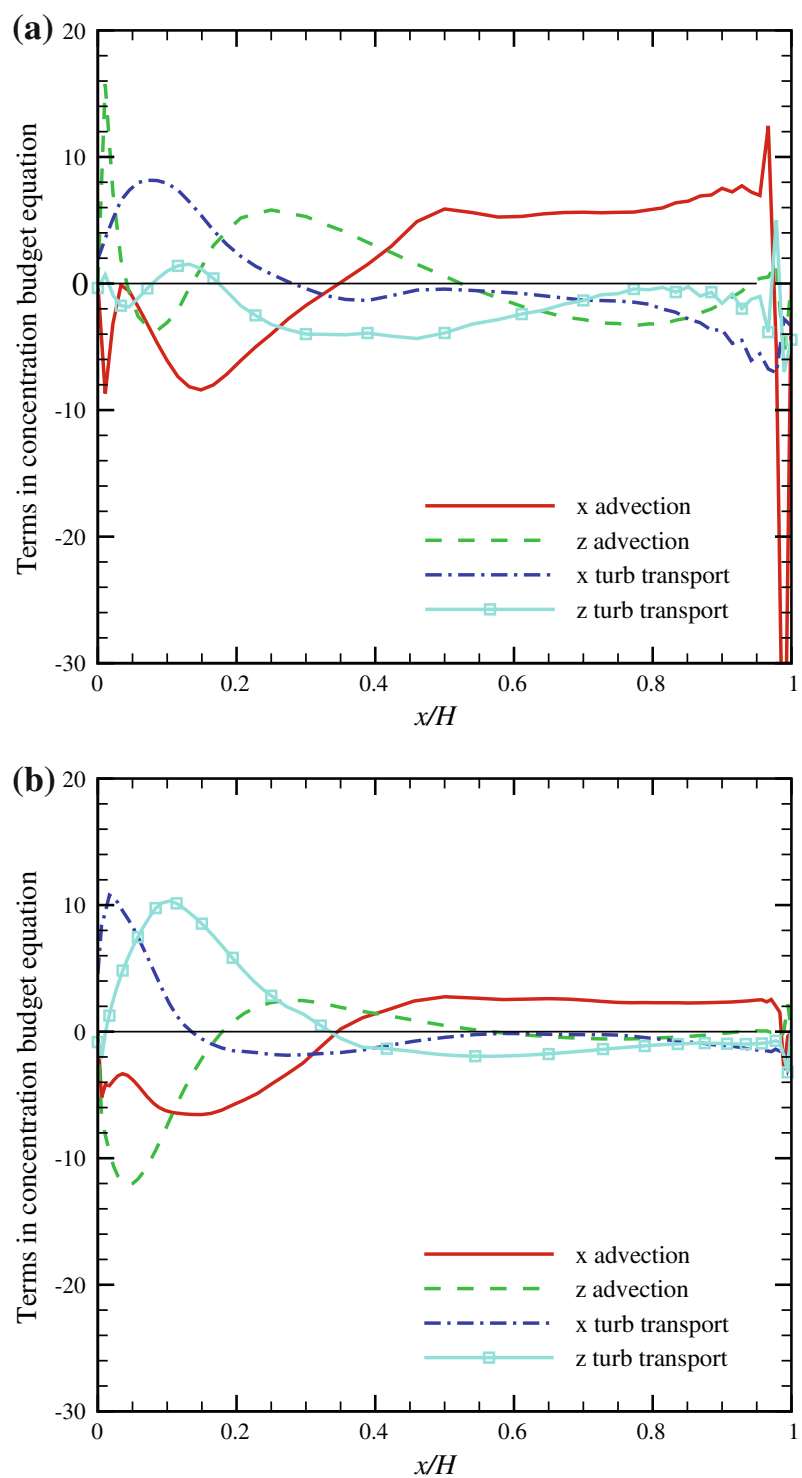

Fig. 12 Horizontal distribution of the terms in the normalised pollutant concentration budget equation (16) along the roof level. $R i$ : $\mathbf{a} 0 ; \mathbf{b}-2.4$

anthropogenic contributions to ground heating have undesirable energy cost and associated carbon emissions.

\section{Conclusion}

We employed LES to investigate the flow field and pollutant dispersion inside an urban street canyon of aspect ratio 1 with different ground heating intensities. The buoyancy force was 
included in the vertical momentum equation and the transport equation for subgrid-scale TKE with the Boussinesq approximation. Four cases with $R i=0,-0.6,-1.2$, and -2.4 were studied to explore the effects of ground heating on the wind and thermal environment and pollutant dispersion in urban areas.

Although the cases studied here did not show significant changes in flow pattern, the mean flow was observed to be no longer isolated from the free stream when the ground was heated. Some enhancements in both streamwise and vertical velocities and turbulence were found.

It was shown that increased ground heating facilitates the removal of pollutant from the street canyon, and is a natural consequence of the increased updraft, turbulent mixing and pollutant flux resulting from ground heating. The weaker shear layer observed at roof level with increasing heating intensity and the coupled mean flow inside and above the street canyon also contribute to the pollutant removal. But this achievement is at the expense of higher temperatures that may be noticeable to city occupants and pedestrians.

Acknowledgements This project was funded by Singapore National Research Foundation (NRF) through the Singapore-MIT Alliance for Research and Technology (SMART) Center for Environmental Sensing and Modeling (CENSAM).

Open Access This article is distributed under the terms of the Creative Commons Attribution Noncommercial License which permits any noncommercial use, distribution, and reproduction in any medium, provided the original author(s) and source are credited.

\section{References}

Baik JJ, Kim JJ (1999) A numerical study of flow and pollutant dispersion characteristics in urban street canyons. J Appl Meteorol 38:1576-1589

Britter RE, Hanna SR (2003) Flow and dispersion in urban areas. Annu Rev Fluid Mech 35:469-496

Ca VT, Asaeda T, Ito M, Armfield S (1995) Characteristics of wind field in a street canyon. J Wind Eng Ind Aerodyn 57(1):63-80

Cai XM, Barlow JF, Belcher SE (2008) Dispersion and transfer of passive scalars in and above street canyons-large-eddy simulations. Atmos Environ 42:5885-5895

Caton F, Britter RE, Dalziel S (2003) Dispersion mechanism in a street canyon. Atmos Environ 37:693-702

Chang CH, Meroney RN (2003) Concentration and flow distributions in urban street canyons: wind tunnel and computational data. J Wind Eng Ind Aerodyn 91:1141-1154

Chan TL, Dong G, Leung CW, Cheung CS, Hung WT (2002) Validation of a two-dimensional pollutant dispersion model in an isolated street canyon. Atmos Environ 36:861-872

DePaul FT, Sheih CM (1985) A tracer study of dispersion in an urban street canyon. Atmos Environ 19(4):555559

Hoydysh WG, Griffiths RA, Ogawa Y (1974) A scale model study of the dispersion of pollution in street canyons. APCA paper no. 74-157, 67th annual meeting of the air pollution control association, Denver, $\mathrm{CO}$

Huang H, Akutsu Y, Arai M, Tamura M (2000) A two-dimensional air quality model in an urban street canyon: evaluation and sensitivity analysis. Atmos Environ 34:689-698

Jeong SJ, Andrews MJ (2002) Application of the $k-\varepsilon$ turbulence model to the high Reynolds number skimming flow field of an urban street canyon. Atmos Environ 36:1137-1145

Johnson GT, Hunter LJ (1998) Urban wind flows: wind tunnel and numerical simulations-a preliminary comparison. Environ Model Softw 13:279-286

Kastner-Klein P, Fedorovich E, Rotach MW (2001) A wind tunnel study of organised and turbulent air motions in urban street canyons. J Wind Eng Ind Aerodyn 89:849-861

Kim JJ, Baik JJ (2001) Urban street-canyon flows with bottom heating. Atmos Environ 35:3395-3404

Kovar-Panskus A, Moulinneuf L, Savory E, Abdelqari A, Sini JF, Rosant JM, Robins A, Toy N (2002) A wind tunnel investigation of the influence of solar-induced wall-heating on the flow regime within a simulated urban street canyon. Water Air Soil Pollut 2(5-6):555-571 
Letzel MO, Krane M, Raasch S (2008) High resolution urban large-eddy simulation studies from street canyon to neighbourhood scale. Atmos Environ 42:8770-9784

Li XX (2008) Large-eddy simulation of wind flow and air pollutant transport inside urban street canyons of different aspect ratios. PhD thesis, The University of Hong Kong, 205 pp

Li XX, Liu CH, Leung DYC (2005) Development of a $k-\varepsilon$ model for the determination of air exchange rates for street canyons. Atmos Environ 39(38):7285-7296

Li XX, Liu CH, Leung DYC, Lam KM (2006) Recent progress in CFD modelling of wind field and pollutant transport in street canyons. Atmos Environ 40(29):5640-5658

Li XX, Leung DYC, Liu CH, Lam KM (2008a) Physical modeling of flow field inside urban street canyons. J Appl Meteorol Climatol 47(7):2058-2067

Li XX, Liu CH, Leung DYC (2008b) Large-eddy simulation of flow and pollutant dispersion in urban street canyons with wall model. Boundary-Layer Meteorol 129(2):249-268

Li XX, Liu CH, Leung DYC (2009) Numerical investigation of pollutant transport characteristics inside deep urban street canyons. Atmos Environ 43(15):2410-2418

Li XX, Liu CH, Leung DYC (2010) Development of a parallel FEM LES with one-equation subgrid-scale model for incompressible flows. Int J Comput Fluid D 24(1):37-49

Liu CH, Leung DYC (2006) Finite element solution to passive scalar transport behind line sources under neutral and unstable stratification. Int J Numer Methods Fluids 50(5):623-648

Liu CH, Barth MC, Leung DYC (2004) Large-eddy simulation of flow and pollutant transport in street canyons of different building-height-to-street-width ratios. J Appl Meteorol 43:1410-1424

Liu CH, Leung DYC, Barth MC (2005) On the prediction of air and pollutant exchange rates in street canyons of different aspect ratios using large-eddy simulation. Atmos Environ 39:1567-1574

Louka P, Belcher SE, Harrison RG (2000) Coupling between air flow in streets and the well-developed boundary layer aloft. Atmos Environ 34:2613-2621

Meroney RN, Pavageau M, Rafadalis S, Schatzmann M (1996) Study of line source characteristics for 2D physical modelling of pollutant dispersion in street canyons. J Wind Eng Ind Aerodyn 62:37-56

Moeng CH (1984) A large-eddy-simulation model for the study of planetary boundary-layer turbulence. J Atmos Sci 4(13):2052-2062

Niachou K, Livada L, Santamouris M (2008) Experimental study of temperature and airflow distribution inside an urban street canyon during hot summer weather conditions-part I: air and surface temperatures. Build Environ 43:1383-1392

Oke T (1988) Street design and urban canopy layer climate. Energy Build 11:103-113

Pavageau M, Schatzmann M (1999) Wind tunnel measurements of concentration fluctuations in an urban street canyon. Atmos Environ 33:3961-3971

Qin Y, Kot SC (1993) Dispersion of vehicular emission in street canyons, Guangzhou city, South China (PRC). Atmos Environ 27B:283-291

Saiki EM, Moeng CH, Sullivan PP (2000) Large-eddy simulation of the stably stratified planetary boundary layer. Boundary-Layer Meteorol 95:1-30

Sasaki H, Miyakoshi H, Ito H (1989) Water flow visualization studies on convective diffusion of layering and leakage in rectangular cavities aside a main flow way. In: Papers on The society of heating, air-conditioning and sanitary engineers of Japan, vol 39, pp 121-131

Sini JF, Anquetin S, Mestayer PG (1996) Pollutant dispersion and thermal effects in urban street canyons. Atmos Environ 30:2659-2677

Uehara K, Murakami S, Oikawa S, Wakamatsu S (2000) Wind tunnel experiments on how thermal stratification affects flow in and above urban street canyons. Atmos Environ 34:1553-1562

Xie S, Zhang Y, Qi L, Tang X (2003) Spatial distribution of traffic-related pollutant concentrations in street canyons. Atmos Environ 37:3213-3224

Xie X, Liu CH, Leung DYC, Leung MKH (2006) Characteristics of air exchange in a street canyon with ground heating. Atmos Environ 40(33):6396-6409

Xie X, Liu CH, Leung DYC (2007) Impact of building facades and ground heating on wind flow and pollutant transport in street canyons. Atmos Environ 41:9030-9049

Yi L, Lim H (2004) Comparison of convective environments in tropical and extratropical atmospheres with 1989-2002 radiosonde data. In: Proceedings of 26th conference on hurricanes and tropical meteorology, Miami, FL, USA, 3-7 May 2004 